Article

\title{
Synthesis and Biological Evaluation of
} Novel 4-Morpholino-7,8-dihydro-5Hthiopyrano[4,3- $d]$ pyrimidine Derivatives Bearing Phenylpyridine/Phenylpyrimidine-Carboxamides

\author{
Huimin Liu ${ }^{1}$, Wenhui Wang ${ }^{2}$, Chengyu Sun ${ }^{2,3}$, Caolin Wang ${ }^{2}$, Wufu Zhu ${ }^{2, *}$ and \\ Pengwu Zheng ${ }^{2, *}$ \\ 1 School of Perfume and Aroma Technology, Shanghai Institute of Technology, Shanghai 201418, China; \\ szliuhm@sit.edu.cn \\ 2 School of Pharmacy, Jiangxi Science \& Technology Normal University, Nanchang 330013, China; \\ wenhui410@126.com (W.W.); sunchengyu0902@126.com (C.S.); wangcllw@126.com (C.W.) \\ 3 Pharmacy Department, The Affiliated Hospital of Chongqing Three Gorges Medical College, \\ Chongqing 404000, China \\ * $\quad$ Correspondence: zhuwf@jxstnu.edu.cn (W.Z.); Zhengpw@126.com (P.Z.); Tel./Fax: +86-791-8380-2393 (P.Z.) \\ Academic Editor: Derek J. McPhee \\ Received: 27 September 2016; Accepted: 26 October 2016; Published: 31 October 2016
}

\begin{abstract}
Four series of novel 4-morpholino-7,8-dihydro-5 $H$-thiopyrano[4,3- $d]$ pyrimidine derivatives 11a-j, 12a-j, 13a-g and 14a-g bearing phenylpyridine/phenylpyrimidine- carboxamide scaffolds were designed, synthesized and their $\mathrm{IC}_{50}$ values against three cancer cell lines (A549, PC-3 and MCF-7) were evaluated. Eleven of the compounds showed moderate cytotoxicity activity against the cancer cell lines. Structure-activity relationships (SARs) and pharmacological results indicated that the introduction of phenylpyridine-carboxamide scaffold was beneficial for the activity. What's more, the oxidation of the sulfur atom in thiopyran and various types of substituents on the aryl group have different impacts on different series of compounds. Furthermore, the positions of aryl group substituents have a slight impact on the activity of the phenylpyridine-carboxamide series compounds.
\end{abstract}

Keywords: thiopyrano[4,3-d]pyrimidine; phenylpyridine/phenylpyrimidine carboxamides; synthesis; cytotoxicity activity; PI3K $\alpha$ kinase

\section{Introduction}

The PI3K/AKT/mTOR signaling cascade is one of the most important intracellular pathways, which is frequently activated in different types of cancer [1]. Inhibition of the PI3K/Akt/mTOR pathway can effectively block the abnormal signal transduction of various growth factors leading to suppression of the occurrence and development of cancer, so it has become a hotspot of cancer prevention and cancer treatment research. Currently, PI3K/Akt/mTOR pathway inhibitors include PI3K inhibitors, Akt inhibitors, mTOR inhibitors and dual PI3K/mTOR inhibitors and representative compounds are GDC-0941, MK-2206, GDC-0349 and NVP-BEZ235, respectively [2] (Figure 1).

According to our previous study [3-5], we modified some 4-morpholino-7,8-dihydro-5Hthiopyrano $[4,3-d]$ pyrimidine derivatives. Firstly, the urea group of compounds I were replaced with an amide scaffold according to the theory of bioisosterism. Secondly, different aromatic heterocycles were introduced on the carboxy-terminal of the amide inspired by compounds II and III. In addition, various $\mathrm{R}$ groups were introduced on the benzene ring to investigate their impact on activity. As a result, four series of 4-morpholino-7,8-dihydro-5 $\mathrm{H}$-thiopyrano[4,3-d]pyrimidine derivatives bearing phenylpyridine/phenylpyrimidine carboxamide scaffolds were designed as PI3K inhibitors and synthesized. 
Herein we disclose the synthesis and antitumor activity of all the target compounds against the A549 (human lung cancer), PC-3 (human prostatic cancer) and MCF-7 (human breast cancer) cancer cell lines, and the anti-PI3K $\alpha$ kinase activity of one selected compound.

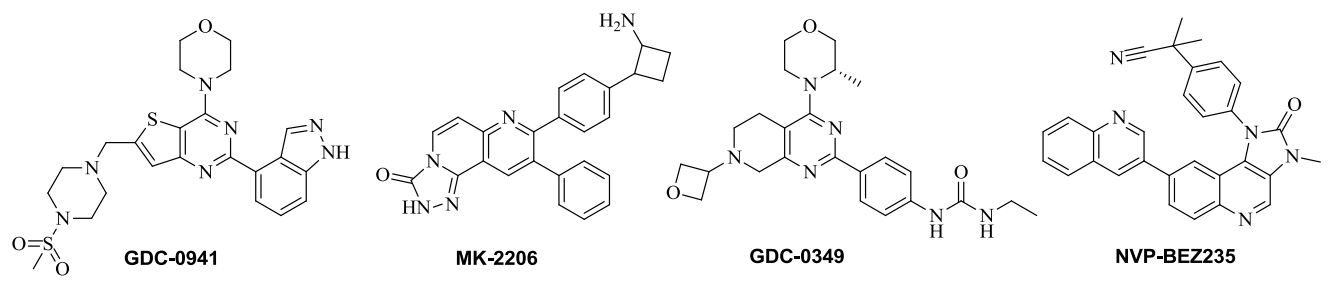

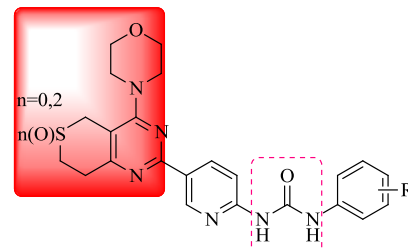

Compounds I

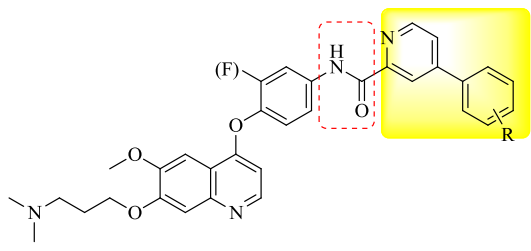

Compounds II

Antitumor agents in our previous research

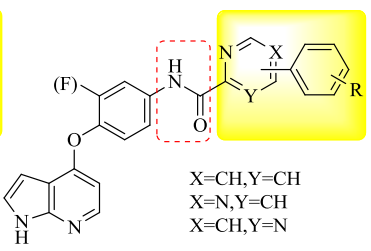

Compounds III

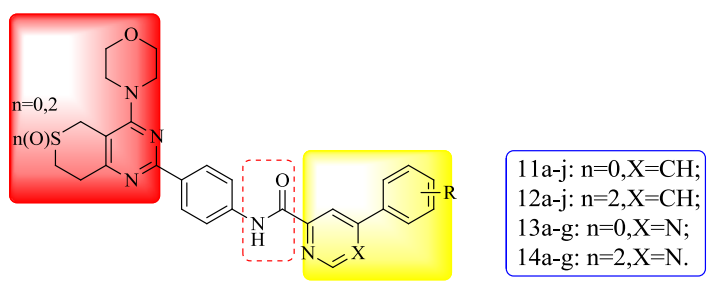

Target compounds

Figure 1. Structures of representative compounds of four kinds of inhibitors and target compounds.

\section{Results and Discussion}

The preparation of target compounds $11 \mathbf{a}-\mathbf{j}, \mathbf{1 2} \mathbf{a}-\mathbf{j}, \mathbf{1 3 a} \mathbf{a}-\mathbf{g}$ and $\mathbf{1 4} \mathbf{a}-\mathbf{g}$ is described in Scheme 1. Compounds $\mathbf{4} \mathbf{a}$ and $\mathbf{4} \mathbf{b}$ were synthesized according to the reported procedures $[3,6,7]$. Compounds $\mathbf{6 a}$ and $\mathbf{6 b}$ were synthesized from $\mathbf{4 a}$ or $\mathbf{4} \mathbf{b}$ and 1-bromo-4-nitrobenzene through Suzuki-coupling reactions, followed by reduction with $80 \% \mathrm{NH}_{2} \mathrm{NH}_{2} \cdot \mathrm{H}_{2} \mathrm{O}$. Compounds $\mathbf{7 a - j}$ and $\mathbf{9 a}-\mathbf{g}$ were synthesized according to the reported procedures $[4,5,8]$. Carbonyl chlorides $8 \mathbf{a}-\mathbf{j}$ and $\mathbf{1 0} \mathbf{a}-\mathbf{g}$ were obtained by $\mathbf{7 a - j}$ and $\mathbf{9 a}-\mathbf{g}$ throng Chlorination. Then, amides $\mathbf{6 a}$ and $\mathbf{6} \mathbf{b}$ were reacted with phenylpyridine carbonyl chlorides $\mathbf{8} \mathbf{a}-\mathbf{j}$ or phenylpyrimidine carbonyl chlorides $10 \mathbf{a}-\mathbf{g}$ which were synthesized according to the reported procedures $[6,7,9]$ through promotion by DMF and DIPEA in dichloromethane to yield the target compounds 11a-j, 12a-j, 13a-g and 14a-g, respectively.

\subsection{Biological Evaluation}

Taking GDC-0941 as reference compound, the target compounds 1a-j, 12a-j, 13a-g and 14a-g ere evaluated for the cytotoxicity against the three cancer cell lines A549, PC-3 and MCF-7 usg 3-(4,5-dimethylthiazolyl-2)-2,5-diphenyltetrazolium bromide (MTT) cell proliferation assays. In addition, one selected compounds $12 \mathrm{~h}$ was fher evaluated for PI3K $\alpha$ kinase inhibitory activity. The results, expressed as $\mathrm{IC}_{50}$ values or inhibitory rate, are sumrized in Tables 1-3. 

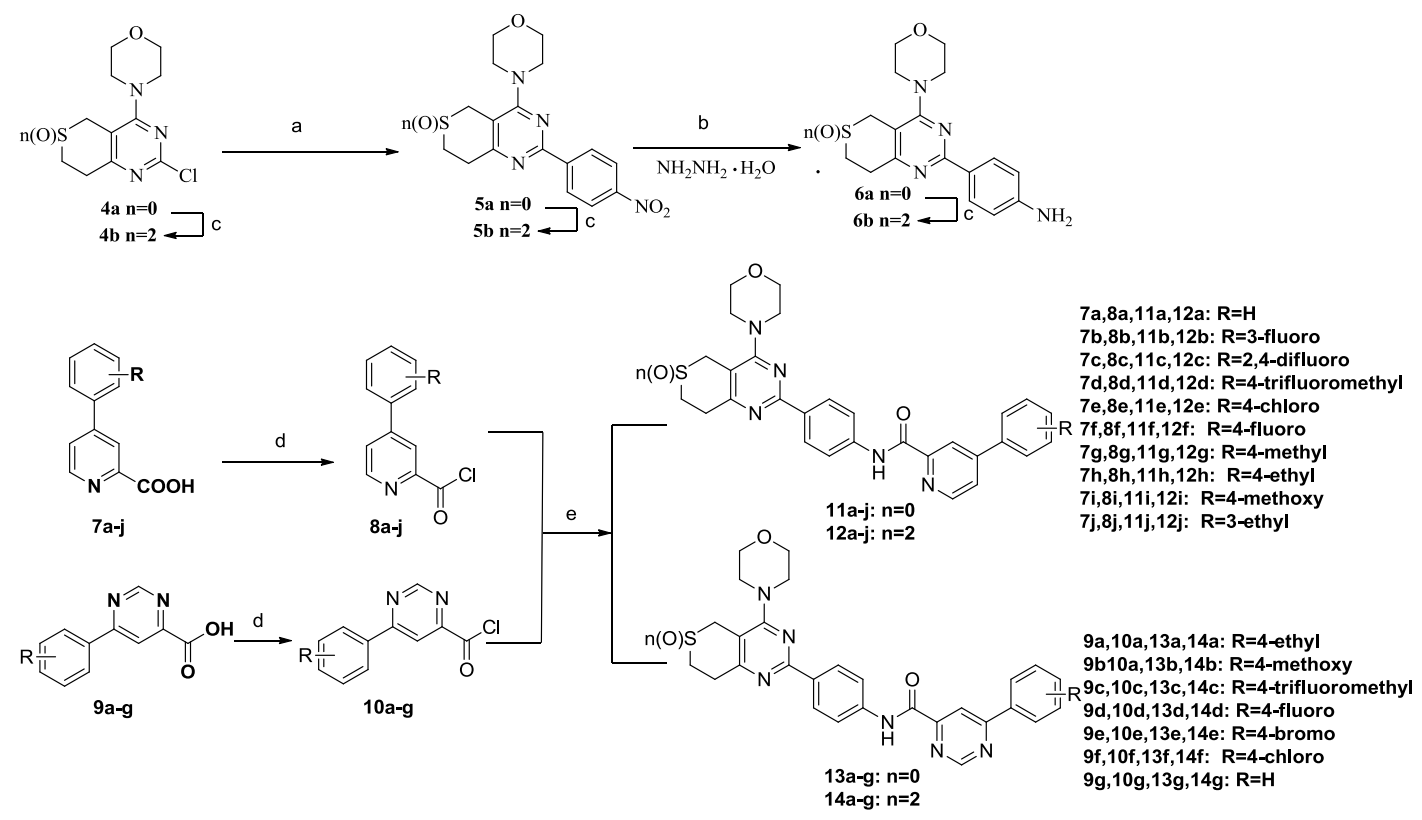

Scheme 1. Synthetic routes to the target compounds. Reagents and conditions: (a) (1) 1-bromo-4-nitrobenzene, bis(pinacolato)diboron, $\mathrm{KAc}, \mathrm{Pd}\left(\mathrm{PPh}_{3}\right) \mathrm{Cl}_{2}$, 1,2-dimethoxyethane, reflux, $2 \mathrm{~h}$; (2) $\mathrm{H}_{2} \mathrm{O}, \mathrm{Na}_{2} \mathrm{CO}_{3}$, $\mathrm{Pd}\left(\mathrm{PPh}_{3}\right)_{2} \mathrm{Cl}_{2}$, reflux, $6 \mathrm{~h}$; (b) $80 \% \mathrm{NH}_{2} \mathrm{NH}_{2} \cdot \mathrm{H}_{2} \mathrm{O}, \mathrm{FeCl}_{3} \cdot 6 \mathrm{H}_{2} \mathrm{O}$, actived $\mathrm{C}$, EtOH, $78{ }^{\circ} \mathrm{C}, 1 \mathrm{~h}$; (c) $\mathrm{Na}_{2} \mathrm{WO}_{4} \cdot 2 \mathrm{H}_{2} \mathrm{O}, 30 \% \mathrm{H}_{2} \mathrm{O}_{2}, 2{ }^{\circ} \mathrm{C}, 3 \mathrm{~h}$; (d) $(\mathrm{COCl})_{2}, \mathrm{DMF}, \mathrm{CH}_{2} \mathrm{Cl}_{2}$, r.t., 0.5 h; (e) DIPEA, $\mathrm{CH}_{2} \mathrm{Cl}_{2}$, r.t., $0.5 \mathrm{~h}$.

Table 1. Structures and cytotoxicity of compounds $\mathbf{1 1 a}-\mathbf{j}$ and $\mathbf{1 2 a}-\mathbf{j}$.

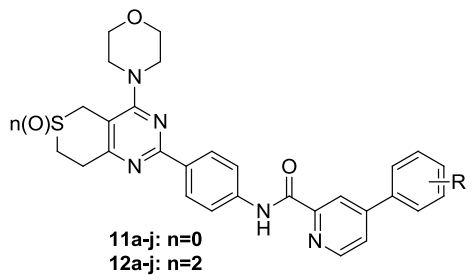

\begin{tabular}{|c|c|c|c|c|c|}
\hline \multirow{2}{*}{ Compound } & \multirow{2}{*}{$\mathbf{n}$} & \multirow{2}{*}{$\mathbf{R}$} & \multicolumn{3}{|c|}{$\mathrm{IC}_{50}(\mu \mathrm{M})^{\mathrm{a}}$} \\
\hline & & & A549 & PC-3 & MCF-7 \\
\hline $11 a$ & 0 & $\mathrm{H}$ & $N A^{c}$ & NA & NA \\
\hline $11 b$ & 0 & 3-fluoro & $48.08 \pm 0.13$ & $60.29 \pm 1.24$ & $51.67 \pm 1.56$ \\
\hline $11 \mathrm{c}$ & 0 & 2,4-difluoro & NA & NA & $\mathrm{NA}$ \\
\hline 11d & 0 & 4-trifluoromethyl & $43.46 \pm 0.12$ & NA & $50.28 \pm 2.18$ \\
\hline $11 \mathrm{e}$ & 0 & 4-chloro & $19.28 \pm 0.86$ & $23.20 \pm 0.76$ & $20.88 \pm 1.02$ \\
\hline $11 \mathrm{f}$ & 0 & 4-fluoro & NA & NA & NA \\
\hline $11 \mathrm{~g}$ & 0 & 4-methyl & NA & NA & NA \\
\hline $11 \mathrm{~h}$ & 0 & 4-ethyl & NA & NA & NA \\
\hline $11 \mathrm{i}$ & 0 & 4-methoxy & $27.68 \pm 0.10$ & $65.66 \pm 0.61$ & $32.37 \pm 1.84$ \\
\hline $11 \mathrm{j}$ & 0 & 3-ethyl & $11.59 \pm 0.11$ & $15.29 \pm 0.83$ & $12.43 \pm 0.96$ \\
\hline $12 a$ & 2 & $\mathrm{H}^{\circ}$ & NA & $74.27 \pm 0.08$ & NA \\
\hline $12 b$ & 2 & 3-fluoro & NA & NA & NA \\
\hline $12 \mathrm{c}$ & 2 & 2,4-difluoro & NA & NA & NA \\
\hline $12 \mathrm{~d}$ & 2 & 4-trifluoromethyl & NA & NA & NA \\
\hline $12 \mathrm{e}$ & 2 & 4-chloro & NA & NA & NA \\
\hline $12 \mathrm{f}$ & 2 & 4-fluoro & NA & NA & NA \\
\hline $12 \mathrm{~g}$ & 2 & 4-methyl & $14.51 \pm 0.10$ & $64.71 \pm 0.17$ & $28.92 \pm 1.29$ \\
\hline $12 \mathrm{~h}$ & 2 & 4-ethyl & $8.37 \pm 0.10$ & $11.34 \pm 0.11$ & $9.26 \pm 0.82$ \\
\hline $12 \mathrm{i}$ & 2 & 4-methoxy & NA & NA & NA \\
\hline $12 j$ & 2 & 3-ethyl & NA & NA & NA \\
\hline GDC-0941 $\mathrm{b}$ & - & - & $6.99 \pm 0.21$ & $0.20 \pm 0.08$ & $0.07 \pm 0.03$ \\
\hline
\end{tabular}

a The values are an average of two separate determinations; ${ }^{\mathrm{b}}$ Used as a positive controls; ${ }^{\mathrm{c}}$ No Activity. 
Table 2. Structures and cytotoxicity of compounds $13 \mathbf{a}-\mathrm{g}$ and $14 \mathrm{a}-\mathrm{g}$.

\begin{tabular}{|c|c|c|c|c|c|}
\hline \multirow{2}{*}{ Compound } & \multirow{2}{*}{$\mathbf{n}$} & \multirow{2}{*}{$\mathbf{R}$} & \multicolumn{3}{|c|}{$\mathrm{IC}_{50}(\mu \mathrm{M})^{\mathrm{a}}$} \\
\hline & & & A549 & PC-3 & MCF-7 \\
\hline $13 a$ & 0 & 4-ethyl & $\mathrm{NA}^{\mathrm{c}}$ & NA & NA \\
\hline $13 b$ & 0 & 4-methoxy & NA & NA & NA \\
\hline $13 c$ & 0 & 4-trifluoromethyl & NA & NA & NA \\
\hline $13 d$ & 0 & 4-fluoro & NA & NA & NA \\
\hline $13 e$ & 0 & 4-bromo & NA & NA & NA \\
\hline $13 \mathrm{f}$ & 0 & 4-chloro & NA & NA & NA \\
\hline $13 g$ & 0 & $\mathrm{H}$ & NA & NA & NA \\
\hline $14 a$ & 2 & 4-ethyl & NA & $81.69 \pm 4.92$ & $38.71 \pm 1.72$ \\
\hline $14 b$ & 2 & 4-methoxy & NA & NA & $89.64 \pm 0.91$ \\
\hline $14 c$ & 2 & 4-trifluoromethyl & NA & NA & NA \\
\hline $14 d$ & 2 & 4-fluoro & NA & NA & NA \\
\hline $14 \mathrm{e}$ & 2 & 4-bromo & NA & NA & $27.37 \pm 1.27$ \\
\hline $14 \mathrm{f}$ & 2 & 4-chloro & NA & NA & NA \\
\hline $14 \mathrm{~g}$ & 2 & $\mathrm{H}$ & NA & NA & NA \\
\hline GDC-0941 b & - & - & $6.99 \pm 0.21$ & $0.20 \pm 0.08$ & $0.07 \pm 0.03$ \\
\hline
\end{tabular}

${ }^{a}$ The values are an average of two separate determinations; ${ }^{b}$ Used as a positive controls; ${ }^{\mathrm{c}}$ No Activity.

Table 3. PI3Ka kinase activity of selected compounds $12 \mathrm{~h}$ and positive controls.

\begin{tabular}{cc}
\hline \multirow{2}{*}{ Compound } & IC $_{50}{ }^{\mathrm{a}}(\mu \mathrm{M})$ \\
\cline { 2 - 2 } & PI3K $\boldsymbol{\alpha}$ \\
\hline 12h & $7.386 \pm 0.194$ \\
GDC-0941 $^{\mathrm{b}}$ & 0.003 \\
PI-103 $^{\mathrm{b}}$ & $0.075 \pm 0.018$
\end{tabular}

a The values are an average of two separate determinations; ${ }^{\mathrm{b}}$ Used as a positive controls.

As shown in Tables 1 and 2, eleven of the compounds showed moderate cytotoxicity activity against the three cancer cells. In the first series (compounds 11a-j), compounds substituted at the aryl group C-3 position displayed better activity than those substituted at the C-4 position, as seen by comparing $11 \mathrm{~b}$ ( $\mathrm{IC}_{50}$ values: $48.08 \pm 0.13 \mu \mathrm{M}, 60.29 \pm 1.24 \mu \mathrm{M}, 51.67 \pm 1.56 \mu \mathrm{M}$ ) and $11 \mathrm{f}$ (no activity against all three cancer lines) or $\mathbf{1 1 j}\left(\mathrm{IC}_{50}\right.$ values: $\left.11.59 \pm 0.11 \mu \mathrm{M}, 15.29 \pm 0.83 \mu \mathrm{M}, 12.43 \pm 0.96 \mu \mathrm{M}\right)$ and $11 \mathrm{~h}$ (no activity against all three cancer lines). What's more, the introduction of electron-donating groups at the C-3 position was likely to enhance the activity, as inferred from $\mathbf{1 1} \mathbf{b}$ and $\mathbf{1 1} \mathbf{j}$. The substituents at the C-4 position had no significant impact on the activity. In the second series (compounds 12a-j), the presence of electron withdrawing groups $\left(-\mathrm{Cl},-\mathrm{F},-\mathrm{CF}_{3}\right)$ cancelled the activity of the target compounds against all three cancer lines, as exemplified by $\mathbf{1 2} \mathbf{b}-\mathbf{f}$. In this case we inferred that compounds substituted at the $\mathrm{C}-4$ position of aryl group might revealed better activity than those substituted at C-3 position by comparing $12 \mathrm{~h}$ ( $\mathrm{IC}_{50}$ values: $8.37 \pm 0.10 \mu \mathrm{M}, 11.34 \pm 0.11 \mu \mathrm{M}, 9.26 \pm 0.81 \mu \mathrm{M}$ ) and $\mathbf{1 2} \mathbf{j}$ (no activity against all three cancer lines). In addition, the presence of electron-donating groups such as methyl and ethyl at the aryl group C-4 position might be appropriate to increase the activity. In the third series (compounds 13a-g), the activity against all the three cancer lines of all the target compounds had vanished. In the fourth series (compounds 14a-g), the compounds with individual 
substituents such as ethyl, methoxy and bromo showed moderate cytotoxicity activity against the MCF-7 cell line.

By comparison, the target compounds bearing phenylpyridine carboxamide scaffold (i.e., 11a-j and 12a-j) showed better activity than those compounds bearing a phenylpyrimidine carboxamide scaffold (compounds 13a-g and 14a-g). What's more, the oxidation of the sulfur atom played no significant impact on the activity in the first two series. However, it seemed to increase the activity in the last two series of compounds. Finally the inhibitory rate against PI3Ka kinase of the selected compound $\mathbf{1 2 h}$ at $10 \mu \mathrm{M}$ was further examined. It exhibited a moderate inhibitory rate against PI3Ka kinase.

\subsection{Molecular Docking Study}

To explore the binding modes of target compounds with the active site of PI3Ka, molecular docking simulation studies were carried out by using SURFLEX-DOCK module of SYBYL package version. Based on the in vitro inhibition results, we selected compound $12 \mathrm{~h}$ as ligand examples, and the structures of PI3Ka (PDB ID code: 4L23 [9]) were selected as the docking models.

The binding modes of compound $\mathbf{1 2} \mathrm{h}$ with the active site of PI3Ka molecular are shown in Figure 2, where as depicted the morpholino groups of compounds $\mathbf{1 2 h}$ and PI103 were almost completely overlapped. In the docking model of compound $12 \mathrm{~h}$ with PI3Ka, we can see the morpholino group formed one hydrogen bond with the VAL815 residue. In addition, the nitrogen atom of the amide group formed one hydrogen bond with the ASP810 residue and the oxygen atom of the amide group also formed three hydrogen bonds with residue LYS802, respectively. The abovementioned SAR analysis and molecular docking study results may allow the rational design of potential PI3K inhibitors.

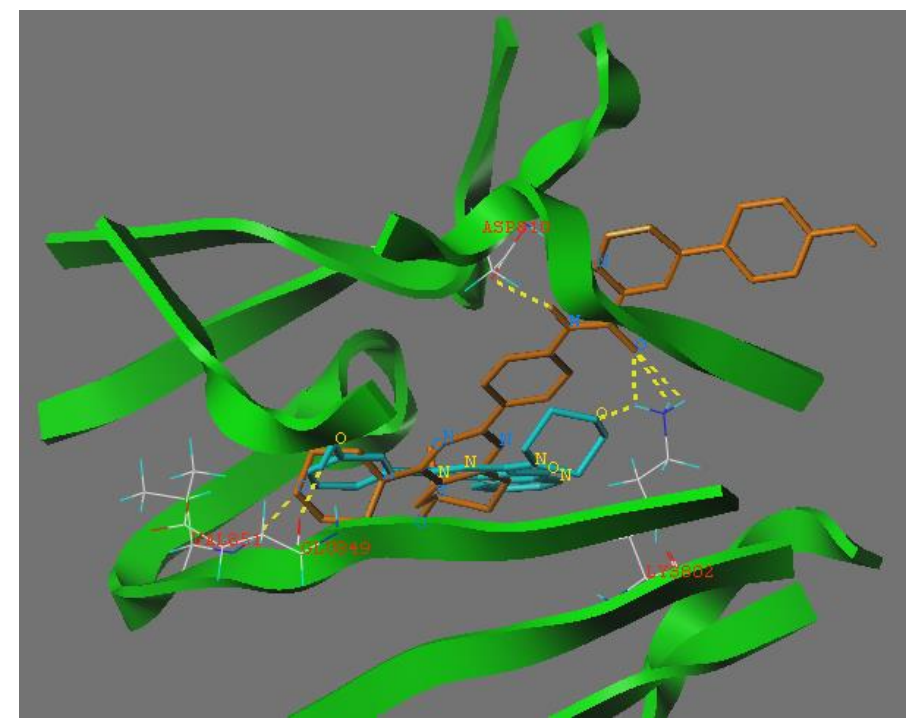

Figure 2. Binding models of compound $\mathbf{1 2}$ h (shown in orange sticks) and native ligand PI 103 (shown in blue sticks) with PI3Ka. The proteins were displayed by green ribbon. Hydrogen bonds were showed in dashed lines (yellow).

\section{Experimental Section}

\subsection{General Information}

All melting points were obtained on a Büchi Melting Point B-540 apparatus (Büchi Labortechnik, Flawil, Switzerland) and were uncorrected. NMR spectra were recorded using a Bruker $400 \mathrm{MHz}$ spectrometer (Bruker Bioscience, Billerica, MA, USA) with TMS as an internal standard. Mass spectra (MS) were taken in ESI mode on an Agilent 1100 LCMS (Agilent, Palo Alto, CA, USA). TLC analysis was carried out on silica gel plates GF254 (Qingdao Haiyang Chemical, Qingdao, China). All the 
materials were obtained from commercial suppliers and used without purification, unless otherwise specied. Yields were not optimized.

\subsection{Chemistry}

\subsubsection{General Procedure for the Preparation of Compounds $\mathbf{4 a} \mathbf{a}, \mathbf{b}, \mathbf{5} \mathbf{a}, \mathbf{b}$ and $\mathbf{6} \mathbf{a}, \mathbf{b}$}

Compounds $4 \mathbf{a}, \mathbf{b}$ were synthesized according to the procedures previously reported by our research group [3,6,7]. A solution of 1-bromo-4-nitrobenzene (5.0 g, $0.029 \mathrm{~mol})$, bis(pinacolato) diboron $(11.1 \mathrm{~g}, 0.043 \mathrm{~mol})$, potassium acetate $(8.7 \mathrm{~g}, 0.089 \mathrm{~mol})$ and bistriphenylphosphine palladium dichloride $(0.5 \mathrm{~g}, 0.7 \mathrm{mmol})$ was added to 1,4 -dioxane $(250 \mathrm{~mL})$ and heated to $110^{\circ} \mathrm{C}$. The reaction was continued for $2.5 \mathrm{~h}$ under $\mathrm{N}_{2}$ and monitored by TLC. $\mathrm{H}_{2} \mathrm{O}(40 \mathrm{~mL})$ was added to the solution and continued for $5 \mathrm{~min}$. Subsequently, $4 \mathbf{a}$ or $4 \mathbf{b}(5.9 \mathrm{~g}, 0.021 \mathrm{~mol}), \mathrm{Na}_{2} \mathrm{CO}_{3}(4.7 \mathrm{~g}, 0.044 \mathrm{~mol})$ and bistriphenylphosphine dichloride $(0.5 \mathrm{~g}, 0.7 \mathrm{mmol})$ were added successively. The reaction was continued for about $6 \mathrm{~h}$. The mixture was cooled and concentrated under vacuum. $\mathrm{H}_{2} \mathrm{O}(250 \mathrm{~mL})$ was added, stirred for $30 \mathrm{~min}$ and then filtered. The filter cake was decolorized with activated carbon ( $5 \mathrm{~g})$ and silica gel (2 g) in a mixed solvent $\left(\mathrm{CH}_{2} \mathrm{Cl}_{2}: \mathrm{CH}_{3} \mathrm{OH}=4: 1,500 \mathrm{~mL}\right)$, filtered while hot and concentrated under vacuum to obtain $5 \mathbf{a}$ or $5 \mathbf{b}$ which was recrystallized from ethanol.

Then $5 \mathbf{a}$ or $5 \mathbf{b}(0.020 \mathrm{~mol})$ was refluxed with hydrazine hydrate $(0.2 \mathrm{~mol})$, Ferric chloride $(0.01 \mathrm{~mol})$ and an appropriate amount of activated carbon in ethanol $(100 \mathrm{~mL})$ for $10 \mathrm{~min}$ and monitored by TLC. The reaction solution was cooled. Then the insoluble solid was filtered, the filtrate was evaporated, after that water was added and stirred at room temperature for $30 \mathrm{~min}$. Afterwards, the yellow solid was filtered off and dried to obtain the desired target compounds $\mathbf{6 a}$ or $\mathbf{6} \mathbf{b}$.

\subsubsection{General Procedure for the Preparation of Compounds $\mathbf{7 a}-\mathbf{j}, \mathbf{8 a}-\mathbf{j}, \mathbf{9 a}-\mathbf{g}$ and $\mathbf{1 0 a}-\mathbf{g}$}

Compounds $\mathbf{7 a}-\mathbf{j}$ and $\mathbf{9 a}-\mathbf{g}$ were synthesized according to the procedures reported by our research group $[4,5,8]$. Then compounds $7 \mathbf{a}-\mathbf{j}$ or $9 \mathbf{a}-\mathbf{g}(0.02 \mathrm{mmol})$ were dissolved in thionyl chloride $(8 \mathrm{~mL})$ and refluxed for $1 \mathrm{~h}$. The reaction mixture was evaporated to yield the corresponding chloride which was dissolved in dichloromethane $(10 \mathrm{~mL})$. The solution $(\mathbf{8} \mathbf{a}-\mathbf{j}$ or $\mathbf{1 0 a}-\mathbf{g})$ was used for the next step without further purification.

\subsubsection{General Procedure for the Preparation of Target Compounds $11 \mathbf{a}-\mathbf{j}, \mathbf{1 2} \mathbf{a}-\mathbf{j}, \mathbf{1 3} \mathbf{a}-\mathbf{g}$ and $14 \mathbf{a}-\mathbf{g}$}

A solution of phenylpyrimidine chloride $(0.01 \mathrm{~mol}, \mathbf{8} \mathbf{a}-\mathbf{j}$ and $\mathbf{1 0 a}-\mathbf{g})$ in dichloromethane $(10 \mathrm{~mL})$ was added dropwise to a solution of $\mathbf{6 a}$ or $\mathbf{6 b}(0.075 \mathrm{~mol})$ and $N, N$-diisopropylethylamine $(0.03 \mathrm{~mol})$ in dichloromethane $(10 \mathrm{~mL})$ in an ice bath. Upon completion of the addition, the reaction mixture was removed from the ice bath, held at room temperature for $15 \mathrm{~min}$ and monitored by thin-layer chromatography (TLC). The mixture was washed with $10 \% \mathrm{~K}_{2} \mathrm{CO}_{3}(50 \mathrm{~mL} \times 3)$ followed by brine $(50 \mathrm{~mL} \times 1)$, and the organic phase was separated, dried over anhydrous sodium sulfate, and evaporated to yield the target compounds $\mathbf{1 1 a}-\mathbf{1 1} \mathbf{j}, \mathbf{1 2 a}-\mathbf{1 2} \mathbf{j}, \mathbf{1 3 a}-\mathbf{1 3} \mathbf{g}$ and $\mathbf{1 4 a - 1 4} \mathbf{g}$, which were recrystallized from isopropanol.

N-(4-(4-Morpholino-7,8-dihydro-5H-thiopyrano[4,3-d]pyrimidin-2-yl)phenyl)-4-phenylpyridine carboxamide (11a). A pale yellow solid; Yield: 66.8\%; m.p.: 244.1-242.8 ${ }^{\circ} \mathrm{C}$; ESI-MS [M + H] m/z: $510.2 ;{ }^{1} \mathrm{H}-\mathrm{NMR}$ $\left(\mathrm{CDCl}_{3}\right) \delta 10.55(\mathrm{~s}, 1 \mathrm{H}), 8.75(\mathrm{~d}, J=5.1 \mathrm{~Hz}, 1 \mathrm{H}), 8.71(\mathrm{~d}, J=8.3 \mathrm{~Hz}, 2 \mathrm{H}), 8.65(\mathrm{~s}, 1 \mathrm{H}), 8.04(\mathrm{~d}, J=8.2 \mathrm{~Hz}$, $2 \mathrm{H}), 7.77(\mathrm{~d}, J=3.8 \mathrm{~Hz}, 1 \mathrm{H}), 7.60(\mathrm{~d}, J=7.7 \mathrm{~Hz}, 1 \mathrm{H}), 7.52(\mathrm{~s}, 1 \mathrm{H}), 7.52-7.48(\mathrm{~m}, 1 \mathrm{H}), 7.47(\mathrm{~s}, 1 \mathrm{H})$, $7.20(\mathrm{~d}, J=2.1 \mathrm{~Hz}, 1 \mathrm{H}), 3.95(\mathrm{~s}, 4 \mathrm{H}), 3.89(\mathrm{~s}, 6 \mathrm{H}), 3.64(\mathrm{~s}, 2 \mathrm{H}), 3.04(\mathrm{~s}, 2 \mathrm{H})$.

N-(4-(4-Morpholino-7,8-dihydro-5H-thiopyrano[4,3-d]pyrimidin-2-yl)phenyl)-4-(3-fluorophenyl)pyridine amide (11b). A pale yellow solid; Yield: 65.3\%; m.p.: 236.5-238.4 ${ }^{\circ} \mathrm{C}$; ESI-MS [M + H] m/z: 528.1; ${ }^{1} \mathrm{H}-\mathrm{NMR}\left(\mathrm{CDCl}_{3}\right) \delta 11.02(\mathrm{~s}, 1 \mathrm{H}), 8.95(\mathrm{~s}, 1 \mathrm{H}), 8.82(\mathrm{~d}, J=5.4 \mathrm{~Hz}, 1 \mathrm{H}), 8.63(\mathrm{~d}, J=8.7 \mathrm{~Hz}, 2 \mathrm{H})$, $8.08(\mathrm{~d}, J=8.7 \mathrm{~Hz}, 2 \mathrm{H}), 7.91(\mathrm{~d}, J=2.1 \mathrm{~Hz}, 2 \mathrm{H}), 7.90(\mathrm{~s}, 1 \mathrm{H}), 7.56(\mathrm{~s}, 1 \mathrm{H}), 7.54(\mathrm{~d}, J=1.8 \mathrm{~Hz}, 1 \mathrm{H})$, $3.95(\mathrm{~s}, 4 \mathrm{H}), 3.87(\mathrm{~s}, 4 \mathrm{H}), 3.84(\mathrm{~s}, 2 \mathrm{H}), 3.65(\mathrm{~s}, 2 \mathrm{H}), 3.05(\mathrm{~d}, J=6.0 \mathrm{~Hz}, 2 \mathrm{H})$. 
N-(4-(4-Morpholino-7,8-dihydro-5H-thiopyrano[4,3-d]pyrimidin-2-yl)phenyl)-4-(2,4-difluorophenyl) picolinamide (11c). A pale yellow solid; Yield: 66.6\%; m.p.: 235.0-236.7 ${ }^{\circ} \mathrm{C}$; ESI-MS [M + H] m/z: 546.1; ${ }^{1} \mathrm{H}-\mathrm{NMR}\left(\mathrm{CDCl}_{3}\right) \delta 10.42(\mathrm{~s}, 1 \mathrm{H}), 8.73(\mathrm{~d}, J=3.1 \mathrm{~Hz}, 2 \mathrm{H}), 8.72(\mathrm{~s}, 1 \mathrm{H}), 8.49(\mathrm{~s}, 1 \mathrm{H}), 8.03(\mathrm{~d}, J=8.5 \mathrm{~Hz}$, $2 \mathrm{H}), 7.74-7.71(\mathrm{~m}, 1 \mathrm{H}), 7.61(\mathrm{td}, J=8.7,6.3 \mathrm{~Hz}, 1 \mathrm{H}), 7.07(\mathrm{td}, J=8.1,2.3 \mathrm{~Hz}, 1 \mathrm{H}), 7.00(\mathrm{ddd}, J=11.0,8.7$, $2.5 \mathrm{~Hz}, 1 \mathrm{H}), 3.94(\mathrm{~s}, 4 \mathrm{H}), 3.89(\mathrm{~s}, 6 \mathrm{H}), 3.62(\mathrm{~s}, 2 \mathrm{H}), 3.04(\mathrm{~s}, 2 \mathrm{H})$.

N-(4-(4-Morpholino-7,8-dihydro-5H-thiopyrano[4,3-d]pyrimidin-2-yl)phenyl)-4-(4-trifluoromethylphenyl) picolinamide (11d). A yellow solid; Yield: 64.9\%; m.p.: 229.3-231.7 ${ }^{\circ} \mathrm{C}$; ESI-MS [M + H] m/z: 578.2 ; ${ }^{1} \mathrm{H}-\mathrm{NMR}\left(\mathrm{DMSO}-\mathrm{d}_{6}\right) \delta 10.86(\mathrm{~s}, 1 \mathrm{H}), 8.87(\mathrm{~s}, 1 \mathrm{H}), 8.47(\mathrm{~s}, 1 \mathrm{H}), 8.34(\mathrm{~d}, J=8.3 \mathrm{~Hz}, 2 \mathrm{H}), 8.13(\mathrm{~d}, J=7.5 \mathrm{~Hz}$, 2H), $8.07(\mathrm{~s}, 2 \mathrm{H}), 8.05(\mathrm{~s}, 1 \mathrm{H}), 7.93(\mathrm{~d}, J=7.9 \mathrm{~Hz}, 2 \mathrm{H}), 3.76(\mathrm{~s}, 4 \mathrm{H}), 3.71(\mathrm{~s}, 2 \mathrm{H}), 3.39(\mathrm{~s}, 4 \mathrm{H}), 3.07(\mathrm{~s}, 2 \mathrm{H})$, $3.00(\mathrm{~s}, 2 \mathrm{H})$.

N-(4-(4-Morpholino-7,8-dihydro-5H-thiopyrano[4,3-d]pyrimidin-2-yl)phenyl)-4-(4-chlorophenyl)pyridine amide (11e). A pale yellow solid; Yield: 65.1\%; m.p.: 235.3-236.2 ${ }^{\circ} \mathrm{C}$; ESI-MS [M + H] m/z: 545.2; ${ }^{1} \mathrm{H}-\mathrm{NMR}\left(\mathrm{CDCl}_{3}\right) \delta 12.09$ (s, 1H), $9.81(\mathrm{~s}, 1 \mathrm{H}), 9.14(\mathrm{~s}, 1 \mathrm{H}), 8.30(\mathrm{~s}, 3 \mathrm{H}), 8.23(\mathrm{~s}, 2 \mathrm{H}), 8.10(\mathrm{~s}, 2 \mathrm{H})$, $7.56(\mathrm{~s}, 2 \mathrm{H}), 3.95(\mathrm{~s}, 4 \mathrm{H}), 3.88(\mathrm{~s}, 4 \mathrm{H}), 3.75(\mathrm{~s}, 2 \mathrm{H}), 3.68(\mathrm{~s}, 2 \mathrm{H}), 3.08(\mathrm{~s}, 2 \mathrm{H})$.

N-(4-(4-Morpholino-7,8-dihydro-5H-thiopyrano[4,3-d]pyrimidin-2-yl)phenyl)-4-(4-fluorophenyl)pyridine amide (11f). A yellow solid; Yield: 63.7\%; m.p.: 248.1-249.6 ${ }^{\circ} \mathrm{C}$; ESI-MS [M + H] m/z: 528.2; ${ }^{1} \mathrm{H}-\mathrm{NMR}$ $\left(\mathrm{DMSO}-d_{6}\right) \delta 10.84(\mathrm{~s}, 1 \mathrm{H}), 8.82(\mathrm{~s}, 1 \mathrm{H}), 8.43(\mathrm{~s}, 1 \mathrm{H}), 8.35(\mathrm{~d}, J=8.3 \mathrm{~Hz}, 2 \mathrm{H}), 8.07(\mathrm{~d}, J=8.4 \mathrm{~Hz}, 2 \mathrm{H})$, $8.01(\mathrm{~s}, 3 \mathrm{H}), 7.43(\mathrm{~d}, J=8.8 \mathrm{~Hz}, 2 \mathrm{H}), 3.78(\mathrm{~s}, 4 \mathrm{H}), 3.73(\mathrm{~s}, 2 \mathrm{H}), 3.40(\mathrm{~s}, 4 \mathrm{H}), 3.09(\mathrm{~s}, 2 \mathrm{H}), 3.02(\mathrm{~s}, 2 \mathrm{H})$.

N-(4-(4-Morpholino-7,8-dihydro-5H-thiopyrano[4,3-d]pyrimidin-2-yl)phenyl)-4-(4-methylphenyl) picolinamide (11g). A pale yellow solid; Yield: 64.1\%; m.p.: 275.0-276.8 ${ }^{\circ} \mathrm{C}$; ESI-MS [M + H] m/z: 524.2; ${ }^{1} \mathrm{H}-\mathrm{NMR}$ $\left(\mathrm{DMSO}-d_{6}\right) \delta 10.84(\mathrm{~s}, 1 \mathrm{H}), 8.79(\mathrm{~s}, 1 \mathrm{H}), 8.42(\mathrm{~s}, 1 \mathrm{H}), 8.35(\mathrm{~d}, J=8.0 \mathrm{~Hz}, 2 \mathrm{H}), 8.07(\mathrm{~d}, J=8.7 \mathrm{~Hz}, 2 \mathrm{H})$, $8.02-7.98(\mathrm{~m}, 1 \mathrm{H}), 7.83(\mathrm{~d}, J=7.3 \mathrm{~Hz}, 2 \mathrm{H}), 7.40(\mathrm{~d}, J=7.9 \mathrm{~Hz}, 2 \mathrm{H}), 3.78(\mathrm{~s}, 4 \mathrm{H}), 3.73(\mathrm{~s}, 2 \mathrm{H}), 3.41(\mathrm{~s}, 4 \mathrm{H})$, $3.09(\mathrm{~s}, 2 \mathrm{H}), 3.02(\mathrm{~s}, 2 \mathrm{H}), 2.41(\mathrm{~s}, 3 \mathrm{H})$.

N-(4-(4-Morpholino-7,8-dihydro-5H-thiopyrano[4,3-d]pyrimidin-2-yl)phenyl)-4-(4-ethylphenyl) picolinamide (11h). A pale yellow solid; Yield: 67.3\%; m.p.: 229.8-232.1 ${ }^{\circ} \mathrm{C} ;$ ESI-MS [M + H] m/z: 538.2; ${ }^{1} \mathrm{H}-\mathrm{NMR}$ $\left(\mathrm{DMSO}-d_{6}\right) \delta 10.82(\mathrm{~s}, 1 \mathrm{H}), 8.79(\mathrm{~s}, 1 \mathrm{H}), 8.41(\mathrm{~s}, 1 \mathrm{H}), 8.33(\mathrm{~d}, J=8.4 \mathrm{~Hz}, 2 \mathrm{H}), 8.05(\mathrm{~d}, J=9.1 \mathrm{~Hz}, 2 \mathrm{H})$, $7.99(\mathrm{~s}, 1 \mathrm{H}), 7.83(\mathrm{~d}, J=8.0 \mathrm{~Hz}, 2 \mathrm{H}), 7.41(\mathrm{~d}, J=7.8 \mathrm{~Hz}, 2 \mathrm{H}), 3.76(\mathrm{~s}, 4 \mathrm{H}), 3.71(\mathrm{~s}, 2 \mathrm{H}), 3.37(\mathrm{~s}, 4 \mathrm{H})$, $3.08(\mathrm{~s}, 2 \mathrm{H}), 3.00(\mathrm{~s}, 2 \mathrm{H}), 2.69(\mathrm{~d}, J=7.5 \mathrm{~Hz}, 2 \mathrm{H}), 1.22(\mathrm{~s}, 3 \mathrm{H})$.

N-(4-(4-Morpholino-7,8-dihydro-5H-thiopyrano[4,3-d]pyrimidin-2-yl)phenyl)-4-(4methoxyphenyl) pyridine-carboxamide (11i). A pale yellow solid; Yield: 63.7\%; m.p.: 233.6-235.1 ${ }^{\circ} \mathrm{C}$; ESI-MS [M + H] $m / z$ : 540.2; ${ }^{1} \mathrm{H}-\mathrm{NMR}\left(\mathrm{DMSO}-\mathrm{d}_{6}\right) \delta 10.84(\mathrm{~s}, 1 \mathrm{H}), 8.76(\mathrm{~d}, J=5.2 \mathrm{~Hz}, 1 \mathrm{H}), 8.40(\mathrm{~d}, J=1.3 \mathrm{~Hz}, 1 \mathrm{H}), 8.36(\mathrm{~s}, 1 \mathrm{H})$, $8.34(\mathrm{~s}, 1 \mathrm{H}), 8.08(\mathrm{~s}, 1 \mathrm{H}), 8.06(\mathrm{~s}, 1 \mathrm{H}), 7.98(\mathrm{dd}, J=5.2,1.9 \mathrm{~Hz}, 1 \mathrm{H}), 7.92-7.89(\mathrm{~m}, 1 \mathrm{H}), 7.89(\mathrm{~d}, J=2.1 \mathrm{~Hz}$, $1 \mathrm{H}), 7.14(\mathrm{~d}, J=5.4 \mathrm{~Hz}, 1 \mathrm{H}), 7.13(\mathrm{~s}, 1 \mathrm{H}), 3.85(\mathrm{~s}, 3 \mathrm{H}), 3.80-3.74(\mathrm{~m}, 4 \mathrm{H}), 3.73(\mathrm{~s}, 2 \mathrm{H}), 3.40(\mathrm{~s}, 4 \mathrm{H})$, $3.09(\mathrm{t}, J=6.4 \mathrm{~Hz}, 2 \mathrm{H}), 3.01(\mathrm{t}, J=6.3 \mathrm{~Hz}, 2 \mathrm{H})$.

N-(4-(4-Morpholino-7,8-dihydro-5H-thiopyrano[4,3-d]pyrimidin-2-yl)phenyl)-4-(3-methylphenyl) pyridine carboxamide (11j). A white solid; Yield: $65.6 \%$; m.p.: $>300.0{ }^{\circ} \mathrm{C}$; ESI-MS $[\mathrm{M}+\mathrm{H}] \mathrm{m} / \mathrm{z}: 542.1 ;{ }^{1} \mathrm{H}-\mathrm{NMR}$ $\left(\mathrm{DMSO}-d_{6}\right) \delta 10.83(\mathrm{~s}, 1 \mathrm{H}), 8.80(\mathrm{~s}, 1 \mathrm{H}), 8.41(\mathrm{~s}, 1 \mathrm{H}), 8.34(\mathrm{~d}, J=8.1 \mathrm{~Hz}, 2 \mathrm{H}), 8.05(\mathrm{~d}, J=8.7 \mathrm{~Hz}, 2 \mathrm{H})$, $8.00(\mathrm{~s}, 1 \mathrm{H}), 7.72(\mathrm{~s}, 1 \mathrm{H}), 7.67(\mathrm{~s}, 1 \mathrm{H}), 7.46(\mathrm{~s}, 1 \mathrm{H}), 7.35(\mathrm{~s}, 1 \mathrm{H}), 3.76(\mathrm{~s}, 4 \mathrm{H}), 3.71(\mathrm{~s}, 2 \mathrm{H}), 3.39(\mathrm{~s}, 4 \mathrm{H})$, $3.07(\mathrm{~s}, 2 \mathrm{H}), 3.00(\mathrm{~s}, 2 \mathrm{H}), 2.43(\mathrm{~s}, 3 \mathrm{H})$.

N-(4-(4-Morpholino-7,8-dihydro-6,6-dioxide-5H-thiopyrano[4,3-d]pyrimidin-2-yl)phenyl)-4-phenylpyridine Amide (12a). A white solid; Yield: 61.9\%; m.p.: 229.0-233.8 ${ }^{\circ}$ C; ESI-MS [M + H] m/z: 524.1; ${ }^{1} \mathrm{H}-\mathrm{NMR}$ $\left(\mathrm{DMSO}-d_{6}\right) \delta 10.87(\mathrm{~s}, 1 \mathrm{H}), 8.82(\mathrm{~s}, 1 \mathrm{H}), 8.42(\mathrm{~s}, 1 \mathrm{H}), 8.35(\mathrm{~d}, J=8.6 \mathrm{~Hz}, 2 \mathrm{H}), 8.08(\mathrm{~d}, J=8.4 \mathrm{~Hz}, 2 \mathrm{H})$, $8.02(\mathrm{~s}, 1 \mathrm{H}), 7.90(\mathrm{~d}, J=7.8 \mathrm{~Hz}, 2 \mathrm{H}), 7.57(\mathrm{~d}, J=7.4 \mathrm{~Hz}, 3 \mathrm{H}), 4.35(\mathrm{~s}, 2 \mathrm{H}), 3.76(\mathrm{~s}, 4 \mathrm{H}), 3.56(\mathrm{~s}, 2 \mathrm{H})$, $3.39(\mathrm{~s}, 6 \mathrm{H})$.

N-(4-(4-Morpholino-7,8-dihydro-6,6-dioxide-5H-thiopyrano[4,3-d]pyrimidin-2-yl)phenyl)-4-(3-fluoro-phenyl) pyridinecarboxamide (12b). A white solid; Yield: 62.3\%; m.p.: 281.5-283.8 ${ }^{\circ}$ C; ESI-MS [M + H] m/z: 560.1; 
${ }^{1} \mathrm{H}-\mathrm{NMR}\left(\right.$ DMSO- $\left.d_{6}\right) \delta 10.90(\mathrm{~s}, 1 \mathrm{H}), 8.84(\mathrm{~d}, J=5.1 \mathrm{~Hz}, 1 \mathrm{H}), 8.45(\mathrm{~d}, J=1.2 \mathrm{~Hz}, 1 \mathrm{H}), 8.36(\mathrm{~d}, J=8.8 \mathrm{~Hz}$, $2 \mathrm{H}), 8.09(\mathrm{~d}, J=8.9 \mathrm{~Hz}, 2 \mathrm{H}), 8.07(\mathrm{dd}, J=5.1,1.9 \mathrm{~Hz}, 1 \mathrm{H}), 7.84-7.76(\mathrm{~m}, 2 \mathrm{H}), 7.66-7.60(\mathrm{~m}, 1 \mathrm{H})$, $7.42-7.35(\mathrm{~m}, 1 \mathrm{H}), 4.37(\mathrm{~s}, 2 \mathrm{H}), 3.77(\mathrm{~d}, J=4.5 \mathrm{~Hz}, 4 \mathrm{H}), 3.58(\mathrm{t}, J=6.4 \mathrm{~Hz}, 2 \mathrm{H}), 3.40(\mathrm{t}, J=5.1 \mathrm{~Hz}, 6 \mathrm{H})$.

$\mathrm{N}$-(4-(4-Morpholino-7,8-dihydro-6,6-dioxide-5H-thiopyrano[4,3-d]pyrimidin-2-yl)phenyl)-4-(2,4-difluorophenyl) picolinamide (12c). A pale yellow solid; Yield: 63.0\%; m.p.: 269.0-272.6 ${ }^{\circ} \mathrm{C}$; ESI-MS [M + H] m/z: 578.1; ${ }^{1} \mathrm{H}-\mathrm{NMR}\left(\mathrm{DMSO}-d_{6}\right) \delta 10.91(\mathrm{~s}, 1 \mathrm{H}), 8.86(\mathrm{~d}, J=5.0 \mathrm{~Hz}, 1 \mathrm{H}), 8.36(\mathrm{~d}, J=8.7 \mathrm{~Hz}, 2 \mathrm{H}), 8.32(\mathrm{~s}, 1 \mathrm{H})$, $8.09(\mathrm{~d}, J=8.8 \mathrm{~Hz}, 2 \mathrm{H}), 7.90(\mathrm{~d}, J=5.1 \mathrm{~Hz}, 1 \mathrm{H}), 7.87-7.81(\mathrm{~m}, 1 \mathrm{H}), 7.55-7.47(\mathrm{~m}, 1 \mathrm{H}), 7.32(\mathrm{t}, J=8.3 \mathrm{~Hz}$, $1 \mathrm{H}), 4.37(\mathrm{~s}, 2 \mathrm{H}), 3.78(\mathrm{~s}, 4 \mathrm{H}), 3.57(\mathrm{~d}, J=6.6 \mathrm{~Hz}, 2 \mathrm{H}), 3.40(\mathrm{t}, J=5.2 \mathrm{~Hz}, 6 \mathrm{H})$.

$\mathrm{N}$-(4-(4-Morpholino-7,8-dihydro-6,6-dioxide-5H-thiopyrano[4,3-d]pyrimidin-2-yl)phenyl)-4-(4-trifluoromethylphenyl) pyridinecarboxamide (12d). A white solid; Yield: $62.4 \%$; m.p.: $>300.0^{\circ} \mathrm{C}$; ESI-MS [M + H] $m / z: 610.1 ;{ }^{1} \mathrm{H}-\mathrm{NMR}\left(\mathrm{DMSO}-\mathrm{d}_{6}\right) \delta 10.92(\mathrm{~s}, 1 \mathrm{H}), 8.88(\mathrm{~d}, J=5.1 \mathrm{~Hz}, 1 \mathrm{H}), 8.49(\mathrm{~d}, J=1.2 \mathrm{~Hz}, 1 \mathrm{H})$, $8.35(\mathrm{~s}, 2 \mathrm{H}), 8.15(\mathrm{~d}, J=8.1 \mathrm{~Hz}, 2 \mathrm{H}), 8.11(\mathrm{~s}, 3 \mathrm{H}), 7.94(\mathrm{~d}, J=8.3 \mathrm{~Hz}, 2 \mathrm{H}), 4.37(\mathrm{~s}, 2 \mathrm{H}), 3.81-3.73(\mathrm{~m}, 4 \mathrm{H})$, $3.58(\mathrm{t}, J=6.6 \mathrm{~Hz}, 2 \mathrm{H}), 3.40(\mathrm{~d}, J=4.5 \mathrm{~Hz}, 6 \mathrm{H})$.

N-(4-(4-Morpholino-7,8-dihydro-6,6-dioxide-5H-thiopyrano[4,3-d]pyrimidin-2-yl)phenyl)-4-(4-chloro-phenyl) pyridinecarboxamide (12e). A pale yellow solid; Yield: 62.1\%; m.p.: 266.8-268.8 ${ }^{\circ} \mathrm{C}$; ESI-MS [M $\left.+\mathrm{H}\right]$ $m / z: 577.1 ;{ }^{1} \mathrm{H}-\mathrm{NMR}\left(\mathrm{DMSO}-d_{6}\right) \delta 10.90(\mathrm{~s}, 1 \mathrm{H}), 8.83(\mathrm{~d}, J=5.1 \mathrm{~Hz}, 1 \mathrm{H}), 8.43(\mathrm{~d}, J=1.3 \mathrm{~Hz}, 1 \mathrm{H})$, $8.36(\mathrm{~d}, J=8.8 \mathrm{~Hz}, 2 \mathrm{H}), 8.09(\mathrm{~d}, J=8.9 \mathrm{~Hz}, 2 \mathrm{H}), 8.04(\mathrm{dd}, J=5.2,1.9 \mathrm{~Hz}, 1 \mathrm{H}), 7.98-7.94(\mathrm{~m}, 2 \mathrm{H})$, 7.66-7.62 (m, 2H), $4.37(\mathrm{~s}, 2 \mathrm{H}), 3.80-3.76(\mathrm{~m}, 4 \mathrm{H}), 3.58(\mathrm{t}, J=6.5 \mathrm{~Hz}, 2 \mathrm{H}), 3.40(\mathrm{~s}, 6 \mathrm{H})$.

N-(4-(4-Morpholino-7,8-dihydro-6,6-dioxide-5H-thiopyrano[4,3-d]pyrimidin-2-yl)phenyl)-4-(4-fluoro-phenyl) pyridincarboxamide (12f). A white solid; Yield: $63.3 \%$; m.p.: $>300.0^{\circ} \mathrm{C}$; ESI-MS [M $\left.+\mathrm{H}\right] \mathrm{m} / \mathrm{z}: 560.2$; ${ }^{1} \mathrm{H}-\mathrm{NMR}\left(\mathrm{DMSO}-d_{6}\right) \delta 10.89(\mathrm{~s}, 1 \mathrm{H}), 8.82(\mathrm{~d}, J=5.1 \mathrm{~Hz}, 1 \mathrm{H}), 8.42(\mathrm{~d}, J=1.4 \mathrm{~Hz}, 1 \mathrm{H}), 8.36(\mathrm{~d}, J=8.8 \mathrm{~Hz}$, $2 \mathrm{H}), 8.09(\mathrm{~d}, J=8.9 \mathrm{~Hz}, 2 \mathrm{H}), 8.04-7.96(\mathrm{~m}, 3 \mathrm{H}), 7.42(\mathrm{t}, J=8.8 \mathrm{~Hz}, 2 \mathrm{H}), 4.37(\mathrm{~s}, 2 \mathrm{H}), 3.77(\mathrm{~d}, J=4.8 \mathrm{~Hz}$, $4 \mathrm{H}), 3.57(\mathrm{t}, J=6.5 \mathrm{~Hz}, 2 \mathrm{H}), 3.40(\mathrm{t}, J=5.2 \mathrm{~Hz}, 6 \mathrm{H})$.

N-(4-(4-Morpholino-7,8-dihydro-6,6-dioxide-5H-thiopyrano[4,3-d]pyrimidin-2-yl)phenyl)-4-(4-methylphenyl) pyridinecarboxamide (12g). A pale yellow solid; Yield: 64.1\%; m.p.: 290.2-293.1 ${ }^{\circ} \mathrm{C}$; ESI-MS [M + H] $m / z: 556.2 ;{ }^{1} \mathrm{H}-\mathrm{NMR}\left(\mathrm{CDCl}_{3}\right) \delta 10.88(\mathrm{~s}, 1 \mathrm{H}), 8.78(\mathrm{~d}, J=5.1 \mathrm{~Hz}, 1 \mathrm{H}), 8.40(\mathrm{~s}, 1 \mathrm{H}), 8.35(\mathrm{~d}, J=8.7 \mathrm{~Hz}$, $2 \mathrm{H}), 8.08(\mathrm{~d}, J=8.7 \mathrm{~Hz}, 2 \mathrm{H}), 7.99(\mathrm{~d}, J=5.2 \mathrm{~Hz}, 1 \mathrm{H}), 7.81(\mathrm{~d}, J=8.0 \mathrm{~Hz}, 2 \mathrm{H}), 7.38(\mathrm{~d}, J=8.0 \mathrm{~Hz}, 2 \mathrm{H})$, $4.36(\mathrm{~s}, 2 \mathrm{H}), 3.76(\mathrm{~s}, 4 \mathrm{H}), 3.57(\mathrm{t}, J=6.4 \mathrm{~Hz}, 2 \mathrm{H}), 3.41-3.36(\mathrm{~m}, 6 \mathrm{H}), 2.38(\mathrm{~s}, 3 \mathrm{H})$.

$\mathrm{N}$-(4-(4-Morpholino-7,8-dihydro-6,6-dioxide-5H-thiopyrano[4,3-d]pyrimidin-2-yl)phenyl)-4-(4-ethylphenyl) picolinamide (12h). A pale yellow solid; Yield: 61.8\%; m.p.: 276.8-279. ${ }^{\circ} \mathrm{C}$; ESI-MS [M + H] $\mathrm{m} / z: 570.2$; ${ }^{1} \mathrm{H}-\mathrm{NMR}\left(\right.$ DMSO- $\left.d_{6}\right) \delta 10.88(\mathrm{~s}, 1 \mathrm{H}), 8.79(\mathrm{~d}, J=5.1 \mathrm{~Hz}, 1 \mathrm{H}), 8.42(\mathrm{~d}, J=1.3 \mathrm{~Hz}, 1 \mathrm{H}), 8.36(\mathrm{~d}, J=8.8 \mathrm{~Hz}$, $2 \mathrm{H}), 8.09(\mathrm{~d}, J=8.9 \mathrm{~Hz}, 2 \mathrm{H}), 8.01(\mathrm{dd}, J=5.2,1.9 \mathrm{~Hz}, 1 \mathrm{H}), 7.84(\mathrm{~d}, J=8.2 \mathrm{~Hz}, 2 \mathrm{H}), 7.42(\mathrm{~d}, J=8.2 \mathrm{~Hz}$, $2 \mathrm{H}), 4.37(\mathrm{~s}, 2 \mathrm{H}), 3.80-3.75(\mathrm{~m}, 4 \mathrm{H}), 3.57(\mathrm{t}, J=6.6 \mathrm{~Hz}, 2 \mathrm{H}), 3.40(\mathrm{~s}, 6 \mathrm{H}), 2.70(\mathrm{dd}, J=15.6,8.1 \mathrm{~Hz}, 2 \mathrm{H})$, $1.24(\mathrm{t}, 3 \mathrm{H})$.

N-(4-(4-Morpholino-7,8-dihydro-6,6-dioxide-5H-thiopyrano[4,3-d]pyrimidin-2-yl)phenyl)-4-(4-methoxy-phenyl) pyridinecarboxamide (12i). A white solid; Yield: 63.1\%; m.p.: 289.0-292.1 ${ }^{\circ} \mathrm{C}$; ESI-MS [M + H] m/z: 572.2; ${ }^{1} \mathrm{H}-\mathrm{NMR}\left(\right.$ DMSO- $\left.d_{6}\right) \delta 10.87(\mathrm{~s}, 1 \mathrm{H}), 8.76(\mathrm{~d}, J=5.1 \mathrm{~Hz}, 1 \mathrm{H}), 8.40(\mathrm{~d}, J=1.3 \mathrm{~Hz}, 1 \mathrm{H}), 8.36(\mathrm{~d}, J=8.8 \mathrm{~Hz}$, $2 \mathrm{H}), 8.09(\mathrm{~d}, J=8.8 \mathrm{~Hz}, 2 \mathrm{H}), 7.98(\mathrm{dd}, J=5.2,1.9 \mathrm{~Hz}, 1 \mathrm{H}), 7.90(\mathrm{~d}, J=8.9 \mathrm{~Hz}, 2 \mathrm{H}), 7.13(\mathrm{~d}, J=8.9 \mathrm{~Hz}$, $2 \mathrm{H}), 4.37(\mathrm{~s}, 2 \mathrm{H}), 3.85(\mathrm{~s}, 3 \mathrm{H}), 3.80-3.76(\mathrm{~m}, 4 \mathrm{H}), 3.57(\mathrm{t}, J=6.5 \mathrm{~Hz}, 2 \mathrm{H}), 3.40(\mathrm{t}, J=5.4 \mathrm{~Hz}, 6 \mathrm{H})$.

N-(4-(4-Morpholino-7,8-dihydro-6,6-dioxide-5H-thiopyrano[4,3-d]pyrimidin-2-yl)phenyl)-4-(3-methylphenyl) pyridinecarboxamide (12j). A white solid; Yield: 62.5\%; m.p.: $287.2-290.0{ }^{\circ} \mathrm{C}$; ESI-MS $[\mathrm{M}+\mathrm{H}] \mathrm{m} / z$ : $556.1 ;{ }^{1} \mathrm{H}-\mathrm{NMR}\left(\mathrm{CDCl}_{3}\right) \delta 10.90(\mathrm{~s}, 1 \mathrm{H}), 8.80(\mathrm{~d}, J=5.1 \mathrm{~Hz}, 1 \mathrm{H}), 8.41(\mathrm{~s}, 1 \mathrm{H}), 8.35(\mathrm{~d}, J=8.6 \mathrm{~Hz}, 2 \mathrm{H})$, $8.08(\mathrm{~d}, J=8.8 \mathrm{~Hz}, 2 \mathrm{H}), 8.00(\mathrm{~d}, J=5.2 \mathrm{~Hz}, 1 \mathrm{H}), 7.73(\mathrm{~s}, 1 \mathrm{H}), 7.69(\mathrm{~d}, J=7.9 \mathrm{~Hz}, 1 \mathrm{H}), 7.46(\mathrm{t}, J=7.8 \mathrm{~Hz}$, $1 \mathrm{H}), 7.34(\mathrm{~d}, J=8.2 \mathrm{~Hz}, 1 \mathrm{H}), 4.36(\mathrm{~s}, 2 \mathrm{H}), 3.77(\mathrm{~s}, 4 \mathrm{H}), 3.57(\mathrm{t}, J=6.6 \mathrm{~Hz}, 2 \mathrm{H}), 3.38(\mathrm{~d}, J=5.3 \mathrm{~Hz}, 6 \mathrm{H})$, $2.42(\mathrm{~s}, 3 \mathrm{H})$. 
N-(4-(4-Morpholino-7,8-dihydro-5H-thiopyrano[4,3-d]pyrimidin-2-yl)phenyl)-6-(p-tolyl)pyrimidine-4formamide (13a). A pale yellow solid; Yield: 61.8\%; m.p.: 257.0-259.7 ${ }^{\circ} \mathrm{C}$; ESI-MS [M + H] $m / z: 525.2$; ${ }^{1} \mathrm{H}-\mathrm{NMR}\left(\mathrm{CDCl}_{3}\right) \delta 10.23(\mathrm{~s}, 1 \mathrm{H}), 9.34(\mathrm{~s}, 1 \mathrm{H}), 8.77(\mathrm{~d}, J=8.4 \mathrm{~Hz}, 2 \mathrm{H}), 8.63(\mathrm{~s}, 1 \mathrm{H}), 8.16(\mathrm{~d}, J=7.9 \mathrm{~Hz}$, $2 \mathrm{H}), 8.03(\mathrm{~d}, J=8.4 \mathrm{~Hz}, 2 \mathrm{H}), 7.39(\mathrm{~d}, J=7.8 \mathrm{~Hz}, 2 \mathrm{H}), 3.97(\mathrm{~s}, 4 \mathrm{H}), 3.90(\mathrm{~d}, J=13.0 \mathrm{~Hz}, 6 \mathrm{H}), 3.64(\mathrm{~s}, 2 \mathrm{H})$, $3.05(\mathrm{~s}, 2 \mathrm{H}), 2.48(\mathrm{~s}, 3 \mathrm{H})$.

N-(4-(4-Morpholino-7,8-dihydro-5H-thiopyrano[4,3-d]pyrimidin-2-yl)phenyl)-6-(p-methoxyphenyl) pyridine-4-carboxamide (13b). A pale yellow solid; Yield: 64.1\%; m.p.: 210.0-212.7 ${ }^{\circ}$ C; ESI-MS $[\mathrm{M}+\mathrm{H}] \mathrm{m} / \mathrm{z}: 541.2 ;{ }^{1} \mathrm{H}-\mathrm{NMR}\left(\mathrm{DMSO}_{6}\right) \delta 11.01(\mathrm{~s}, 1 \mathrm{H}), 9.39(\mathrm{~s}, 1 \mathrm{H}), 8.56(\mathrm{~s}, 1 \mathrm{H}), 8.35(\mathrm{t}, J=10.1 \mathrm{~Hz}$, $4 \mathrm{H}), 8.09(\mathrm{~s}, 2 \mathrm{H}), 7.16(\mathrm{~d}, J=8.6 \mathrm{~Hz}, 2 \mathrm{H}), 3.88(\mathrm{~s}, 4 \mathrm{H}), 3.78(\mathrm{~s}, 3 \mathrm{H}), 3.73(\mathrm{~s}, 2 \mathrm{H}), 3.41(\mathrm{~s}, 4 \mathrm{H}), 3.09(\mathrm{~s}, 2 \mathrm{H})$, $3.02(\mathrm{~s}, 2 \mathrm{H})$.

N-(4-(4-Morpholino-7,8-dihydro-5H-thiopyrano[4,3-d]pyrimidin-2-yl)phenyl)-6-(4-trifluoromethylphenyl) pyridine-4-carboxamide (13c). A pale yellow solid; Yield: 61.0\%; m.p.: 244.2-245.8 ${ }^{\circ} \mathrm{C}$; ESI-MS [M + H] m/z: 579.1; ${ }^{1} \mathrm{H}-\mathrm{NMR}\left(\mathrm{CDCl}_{3}\right) \delta 10.11(\mathrm{~s}, 1 \mathrm{H}), 9.40(\mathrm{~s}, 1 \mathrm{H}), 8.69$ (s, 1H), $8.59(\mathrm{~s}, 2 \mathrm{H}), 8.36(\mathrm{~d}, J=8.1 \mathrm{~Hz}$, $2 \mathrm{H}), 7.95(\mathrm{~d}, J=8.3 \mathrm{~Hz}, 2 \mathrm{H}), 7.83(\mathrm{~d}, J=8.4 \mathrm{~Hz}, 2 \mathrm{H}), 3.89(\mathrm{~s}, 4 \mathrm{H}), 3.66(\mathrm{~s}, 2 \mathrm{H}), 3.63(\mathrm{~s}, 4 \mathrm{H}), 3.45(\mathrm{~s}, 2 \mathrm{H})$, $3.04(\mathrm{~s}, 2 \mathrm{H})$.

N-(4-(4-Morpholino-7,8-dihydro-5H-thiopyrano[4,3-d]pyrimidin-2-yl)phenyl)-6-(4-fluorophenyl) pyridine-4-carboxamide (13d). A pale yellow solid; Yield: 65.1\%; m.p.: 237.0-239.3 ${ }^{\circ}$ C; ESI-MS $[\mathrm{M}+\mathrm{H}] \mathrm{m} / \mathrm{z}: 529.1 ;{ }^{1} \mathrm{H}-\mathrm{NMR}\left(\mathrm{CDCl}_{3}\right) \delta 10.16(\mathrm{~s}, 1 \mathrm{H}), 9.33(\mathrm{~s}, 1 \mathrm{H}), 8.70(\mathrm{~d}, J=8.6 \mathrm{~Hz}, 2 \mathrm{H}), 8.59(\mathrm{~s}, 1 \mathrm{H})$, 8.31-8.22 (m, 2H), $7.99(\mathrm{~d}, J=8.6 \mathrm{~Hz}, 2 \mathrm{H}), 7.24(\mathrm{~d}, J=8.6 \mathrm{~Hz}, 2 \mathrm{H}), 3.88(\mathrm{~s}, 8 \mathrm{H}), 3.75(\mathrm{~s}, 2 \mathrm{H}), 3.63(\mathrm{~s}, 2 \mathrm{H})$, $3.03(\mathrm{~s}, 2 \mathrm{H})$.

N-(4-(4-Morpholino-7,8-dihydro-5H-thiopyrano[4,3-d]pyrimidin-2-yl)phenyl)-6-(4-bromophenyl) pyridine-4-carboxamide (13e). A yellow solid; Yield: 61.4\%; m.p.: 251.8-255.0 ${ }^{\circ} \mathrm{C}$; ESI-MS [M + H] $m / z$ : $590.1 ;{ }^{1} \mathrm{H}-\mathrm{NMR}\left(\mathrm{CDCl}_{3}\right) \delta 10.19(\mathrm{~s}, 1 \mathrm{H}), 9.35(\mathrm{~s}, 1 \mathrm{H}), 8.75(\mathrm{~s}, 2 \mathrm{H}), 8.61(\mathrm{~s}, 1 \mathrm{H}), 8.12(\mathrm{~d}, J=8.4 \mathrm{~Hz}, 2 \mathrm{H})$, $8.01(\mathrm{~d}, J=8.2 \mathrm{~Hz}, 2 \mathrm{H}), 7.70(\mathrm{~d}, J=8.3 \mathrm{~Hz}, 2 \mathrm{H}), 3.96(\mathrm{~s}, 4 \mathrm{H}), 3.90(\mathrm{~s}, 4 \mathrm{H}), 3.87-3.81(\mathrm{~m}, 2 \mathrm{H}), 3.63(\mathrm{~s}, 2 \mathrm{H})$, $3.04(\mathrm{~s}, 2 \mathrm{H})$.

N-(4-(4-Morpholino-7,8-dihydro-5H-thiopyrano[4,3-d]pyrimidin-2-yl)phenyl)-6-(4-chlorophenyl) pyridine-4-carboxamide (13f). A yellow solid; Yield: 61.5\%; m.p.: 281.8-285.0 ${ }^{\circ} \mathrm{C}$; ESI-MS [M + H] $m / z$ : 546.1; ${ }^{1} \mathrm{H}-\mathrm{NMR}\left(\mathrm{DMSO}-\mathrm{d}_{6}\right) \delta 11.05(\mathrm{~s}, 1 \mathrm{H}), 9.49(\mathrm{~s}, 1 \mathrm{H}), 8.65(\mathrm{~s}, 1 \mathrm{H}), 8.37(\mathrm{~s}, 4 \mathrm{H}), 8.07(\mathrm{~d}, J=8.4 \mathrm{~Hz}, 2 \mathrm{H})$, $7.68(\mathrm{~d}, J=8.6 \mathrm{~Hz}, 2 \mathrm{H}), 3.77(\mathrm{~s}, 4 \mathrm{H}), 3.72(\mathrm{~s}, 2 \mathrm{H}), 3.40(\mathrm{~s}, 4 \mathrm{H}), 3.09(\mathrm{~s}, 2 \mathrm{H}), 3.01(\mathrm{~s}, 2 \mathrm{H})$.

N-(4-(4-Morpholino-7,8-dihydro-5H-thiopyrano[4,3-d]pyrimidin-2-yl)phenyl)-6-phenylpyridine-4-carboxamide (13g). A yellow solid; Yield: 63.8\%; m.p.: 250.1-252.3 ${ }^{\circ} \mathrm{C}$; ESI-MS [M + H] m/z: $511.2 ;{ }^{1} \mathrm{H}-\mathrm{NMR}$ $\left(\mathrm{DMSO}-d_{6}\right) \delta 11.04(\mathrm{~s}, 1 \mathrm{H}), 9.48(\mathrm{~s}, 1 \mathrm{H}), 8.63(\mathrm{~s}, 1 \mathrm{H}), 8.35(\mathrm{t}, J=7.3 \mathrm{~Hz}, 4 \mathrm{H}), 8.07(\mathrm{~d}, J=8.7 \mathrm{~Hz}, 2 \mathrm{H})$, $7.62(\mathrm{~d}, J=6.6 \mathrm{~Hz}, 3 \mathrm{H}), 3.77(\mathrm{~s}, 4 \mathrm{H}), 3.72(\mathrm{~s}, 2 \mathrm{H}), 3.39(\mathrm{~s}, 4 \mathrm{H}), 3.08(\mathrm{~d}, J=5.6 \mathrm{~Hz}, 2 \mathrm{H}), 3.02(\mathrm{~d}, J=5.6 \mathrm{~Hz}, 2 \mathrm{H})$.

N-(4-(4-Morpholino-7,8-dihydro-6,6-dioxide-5H-thiopyrano[4,3-d]pyrimidin-2-yl)phenyl)-6-(p-tolyl) pyrimidine-4-carboxamide (14a). A pale yellow solid; Yield: 62.7\%; m.p.: 260.1-263.0 ${ }^{\circ}$ C; ESI-MS [M + H] $m / z: 557.2 ;{ }^{1} \mathrm{H}-\mathrm{NMR}\left(\mathrm{DMSO}-d_{6}\right) \delta 11.05(\mathrm{~s}, 1 \mathrm{H}), 9.43(\mathrm{~s}, 1 \mathrm{H}), 8.58(\mathrm{~s}, 1 \mathrm{H}), 8.37(\mathrm{~d}, J=8.6 \mathrm{~Hz}, 2 \mathrm{H})$, $8.24(\mathrm{~d}, J=8.0 \mathrm{~Hz}, 2 \mathrm{H}), 8.09(\mathrm{~d}, J=8.6 \mathrm{~Hz}, 2 \mathrm{H}), 7.41(\mathrm{~d}, J=7.9 \mathrm{~Hz}, 2 \mathrm{H}), 4.38(\mathrm{~s}, 2 \mathrm{H}), 3.78(\mathrm{~s}, 4 \mathrm{H})$, $3.59(\mathrm{t}, J=6.0 \mathrm{~Hz}, 2 \mathrm{H}), 3.40(\mathrm{~d}, J=14.5 \mathrm{~Hz}, 6 \mathrm{H}), 2.41(\mathrm{~s}, 3 \mathrm{H})$.

N-(4-(4-Morpholino-7,8-dihydro-6,6-dioxide-5H-thiopyrano[4,3-d]pyrimidin-2-yl)phenyl)-6-(p-methoxyphenyl) pyridine-4-carboxamide (14b). A yellow solid; Yield: 61.7\%; m.p.: 277.0-279.5 ${ }^{\circ} \mathrm{C}$; ESI-MS [M + H] m/z: 573.1; ${ }^{1} \mathrm{H}-\mathrm{NMR}\left(\mathrm{DMSO}-\mathrm{d}_{6}\right) \delta 11.03(\mathrm{~s}, 1 \mathrm{H}), 9.37(\mathrm{~s}, 1 \mathrm{H}), 8.53(\mathrm{~s}, 1 \mathrm{H}), 8.35(\mathrm{~d}, J=8.4 \mathrm{~Hz}, 2 \mathrm{H})$, $8.30(\mathrm{~d}, J=9.0 \mathrm{~Hz}, 2 \mathrm{H}), 8.07(\mathrm{~d}, J=8.7 \mathrm{~Hz}, 2 \mathrm{H}), 7.12(\mathrm{~d}, J=8.9 \mathrm{~Hz}, 2 \mathrm{H}), 4.35(\mathrm{~s}, 2 \mathrm{H}), 3.85(\mathrm{~s}, 3 \mathrm{H})$, $3.84-3.80(\mathrm{~m}, 2 \mathrm{H}), 3.75(\mathrm{~s}, 4 \mathrm{H}), 3.56(\mathrm{~s}, 6 \mathrm{H})$.

N-(4-(4-Morpholino-7,8-dihydro-6,6-dioxide-5H-thiopyrano[4,3-d]pyrimidin-2-yl)phenyl)-6-(4-trifluoromethylphenyl) pyridine-4-carboxamide (14c). A pale yellow solid; Yield: 62.5\%; m.p.: 287.1-289.2 ${ }^{\circ} \mathrm{C}$; ESI-MS [M + H] m/z: 611.1; ${ }^{1} \mathrm{H}-\mathrm{NMR}\left(\mathrm{DMSO}_{\mathrm{d}}\right) \delta 11.12(\mathrm{~s}, 1 \mathrm{H}), 9.53(\mathrm{~s}, 1 \mathrm{H}), 8.71(\mathrm{~s}, 1 \mathrm{H}), 8.53(\mathrm{~d}, J=7.9 \mathrm{~Hz}$, 
$2 \mathrm{H}), 8.35(\mathrm{~d}, J=8.6 \mathrm{~Hz}, 2 \mathrm{H}), 8.08(\mathrm{~d}, J=8.6 \mathrm{~Hz}, 2 \mathrm{H}), 7.95(\mathrm{~d}, J=7.3 \mathrm{~Hz}, 2 \mathrm{H}), 4.36(\mathrm{~s}, 2 \mathrm{H}), 3.75(\mathrm{~s}, 6 \mathrm{H})$, $3.54(\mathrm{~s}, 6 \mathrm{H})$.

N-(4-(4-Morpholino-7,8-dihydro-6,6-dioxide-5H-thiopyrano[4,3-d]pyrimidin-2-yl)phenyl)-6-(4-fluoro-phenyl) pyridine-4-carboxamide (14d). A yellow solid; Yield: 61.3\%; m.p.: $>300{ }^{\circ} \mathrm{C}$; ESI-MS [M + H] $\mathrm{m} / \mathrm{z}: 561.1$; ${ }^{1} \mathrm{H}-\mathrm{NMR}\left(\mathrm{DMSO}-d_{6}\right) \delta 11.07(\mathrm{~s}, 1 \mathrm{H}), 9.44(\mathrm{~s}, 1 \mathrm{H}), 8.61(\mathrm{~s}, 1 \mathrm{H}), 8.40(\mathrm{~s}, 2 \mathrm{H}), 8.35(\mathrm{~d}, J=8.6 \mathrm{~Hz}, 2 \mathrm{H})$, $8.07(\mathrm{~d}, J=8.2 \mathrm{~Hz}, 2 \mathrm{H}), 7.42(\mathrm{~s}, 2 \mathrm{H}), 4.35(\mathrm{~s}, 2 \mathrm{H}), 3.75(\mathrm{~s}, 6 \mathrm{H}), 3.56(\mathrm{~s}, 6 \mathrm{H})$.

N-(4-(4-Morpholino-7,8-dihydro-6,6-dioxide-5H-thiopyrano[4,3-d]pyrimidin-2-yl)phenyl)-6-(4-bromophenyl) pyridine-4-carboxamide (14e). A yellow solid; Yield: 67.1\%; m.p.: $>300{ }^{\circ} \mathrm{C}$; ESI-MS [M + H] m/z: 622.1; ${ }^{1} \mathrm{H}-\mathrm{NMR}\left(\mathrm{DMSO}-d_{6}\right) \delta 11.06(\mathrm{~s}, 1 \mathrm{H}), 9.46(\mathrm{~s}, 1 \mathrm{H}), 8.63(\mathrm{~s}, 1 \mathrm{H}), 8.34(\mathrm{~d}, J=8.9 \mathrm{~Hz}, 2 \mathrm{H}), 8.27(\mathrm{~d}, J=8.6 \mathrm{~Hz}$, $2 \mathrm{H}), 8.06(\mathrm{~d}, J=8.8 \mathrm{~Hz}, 2 \mathrm{H}), 7.79(\mathrm{~d}, J=8.6 \mathrm{~Hz}, 2 \mathrm{H}), 4.35(\mathrm{~s}, 2 \mathrm{H}), 3.75(\mathrm{~s}, 4 \mathrm{H}), 3.55(\mathrm{~d}, J=6.2 \mathrm{~Hz}, 2 \mathrm{H})$, $3.38(\mathrm{~s}, 6 \mathrm{H})$.

N-(4-(4-Morpholino-7,8-dihydro-6,6-dioxide-5H-thiopyrano[4,3-d]pyrimidin-2-yl)phenyl)-6-(4-chloro-phenyl) pyridine-4-carboxamide (14f). A white solid; Yield: $61.4 \%$; m.p.: $>300{ }^{\circ} \mathrm{C}$; ESI-MS [M + H] $\mathrm{m} / z: 578.1$; ${ }^{1} \mathrm{H}-\mathrm{NMR}\left(\mathrm{DMSO}-d_{6}\right) \delta 11.08(\mathrm{~s}, 1 \mathrm{H}), 9.46(\mathrm{~s}, 1 \mathrm{H}), 8.63(\mathrm{~s}, 1 \mathrm{H}), 8.35(\mathrm{~d}, J=8.5 \mathrm{~Hz}, 4 \mathrm{H}), 8.07(\mathrm{~d}, J=8.7 \mathrm{~Hz}$, $2 \mathrm{H}), 7.65(\mathrm{~d}, J=8.6 \mathrm{~Hz}, 2 \mathrm{H}), 4.35(\mathrm{~s}, 2 \mathrm{H}), 3.75(\mathrm{~s}, 4 \mathrm{H}), 3.55(\mathrm{~d}, J=6.4 \mathrm{~Hz}, 2 \mathrm{H}), 3.38(\mathrm{~s}, 6 \mathrm{H})$.

$\mathrm{N}$-(4-(4-Morpholino-7,8-dihydro-6,6-dioxide-5H-thiopyrano[4,3-d]pyrimidin-2-yl)phenyl)-6-phenylpyridine-4carboxamide (14g). A green solid; Yield: 62.8\%; m.p.: 294.2-296.6 ${ }^{\circ} \mathrm{C}$; ESI-MS [M + H] m/z: 543.2; ${ }^{1} \mathrm{H}-\mathrm{NMR}\left(\mathrm{CDCl}_{3}\right) \delta 10.12(\mathrm{~s}, 1 \mathrm{H}), 9.34(\mathrm{~s}, 1 \mathrm{H}), 8.67(\mathrm{~s}, 1 \mathrm{H}), 8.49(\mathrm{~d}, J=7.8 \mathrm{~Hz}, 2 \mathrm{H}), 8.25(\mathrm{~s}, 2 \mathrm{H})$, $7.93(\mathrm{~d}, J=8.0 \mathrm{~Hz}, 2 \mathrm{H}), 7.59(\mathrm{~s}, 2 \mathrm{H}), 7.58-7.55(\mathrm{~m}, 1 \mathrm{H}), 4.18(\mathrm{~s}, 2 \mathrm{H}), 3.89(\mathrm{~s}, 4 \mathrm{H}), 3.61(\mathrm{~s}, 2 \mathrm{H}), 3.45(\mathrm{~s}, 6 \mathrm{H})$.

${ }^{1} \mathrm{H}-\mathrm{NMR}$ spectra for representative final compounds (11a, 11c, 12d, 12j, 13b, 13d, 14b and 14d) can be seen in Figures S1-S8 in Supplementary Materials.

\subsection{PI3K $\alpha$ Kinase Assay}

The selected compound $\mathbf{1 2 h}$ was tested for its activity against PI3Ka using a Kinase-Glo ${ }^{\circledR}$ Luminescent Kinase Assay (Promega, Madison, WI, USA), with GDC-0941 and PI103 as positive control. The kinase reaction is done in a 384-well black plate. Each well is loaded with $50 \mu \mathrm{L}$ of test items (in $90 \%$ DMSO) and $5 \mu \mathrm{L}$ reaction buffer containing $10 \mu \mathrm{g} / \mathrm{mL}$ PI substrate (L- $\alpha$-phosphatidylinositol; Avanti Polar Lipids (Avanti Polar Lipids, Inc., Alabaster, AL, USA); prepared in 3\% octyl-glucoside) and the PI3Ka protein $10 \mathrm{nM}$ is then added to it. The reaction is started by the addition of $5 \mu \mathrm{L}$ of $1 \mu \mathrm{M}$ ATP prepared in the reaction buffer and is incubated for $60 \mathrm{~min}$ for p110a. It is terminated by the addition of $10 \mu \mathrm{L}$ Kinase-Glo buffer. The plates are then read in a Synergy 2 reader (BioTek, Winooski, VT, USA) for luminescence detection. The assay was repeated two times [3,7].

\subsection{Cytotoxicity Assay In Vitro}

The in vitro cytotoxic activities of all the compounds $\mathbf{1 1 a}-\mathbf{1 1} \mathbf{j}, \mathbf{1 2} \mathbf{a}-\mathbf{1 2} \mathbf{j}, \mathbf{1 3} \mathbf{a}-\mathbf{1 3} \mathrm{g}$ and $\mathbf{1 4 a}-\mathbf{1 4} \mathrm{g}$ was evaluated with A549, PC-3 and MCF-7 cell lines by the standard MTT assay, with GDC-0941 as positive control. The cancer cell lines were cultured in minimum essential medium (MEM) supplement with $10 \%$ fetal bovine serum (FBS). Approximately $4 \times 10^{3}$ cells, suspended in MEM medium, were plated onto each well of a 96-well plate and incubated in $5 \% \mathrm{CO}_{2}$ at $37^{\circ} \mathrm{C}$ for $24 \mathrm{~h}$. The test compounds at indicated final concentrations were added to the culture medium and the cell cultures were continued for $72 \mathrm{~h}$. Fresh MTT was added to each well at a terminal concentration of $5 \mu \mathrm{g} / \mathrm{mL}$ and incubated with cells at $37^{\circ} \mathrm{C}$ for $4 \mathrm{~h}$. The formazan crystals were dissolved in $100 \mu \mathrm{L}$ DMSO each well, and the absorbency at $492 \mathrm{~nm}$ (for absorbance of MTT formazan) and $630 \mathrm{~nm}$ (for the reference wavelength) was measured with an ELISA reader. All of the compounds were tested three times in each of the cell lines. The results expressed as inhibition rates or $\mathrm{IC}_{50}$ (half-maximal inhibitory concentration) were the averages of two determinations and calculated by using the Bacus Laboratories Inc. Slide Scanner (Bliss) software (the Bacus Laboratories Inc. Slide Scanner (BLISS) system, Lombard, IL, USA) [3,7]. 


\subsection{Docking Studies}

For docking purposes, we prepared the receptor proteins PDB ID code: 4L23 (PI3Ka). The threedimensional structure of the PI3Ka were obtained from RCSB Protein Data Bank. We built a small organic molecule set (compound 12h) and used the Gasteiger-Huckel method to optimize the molecular force field and structure. Hydrogen atoms were added to the structure allowing for appropriate ionization at physiological $\mathrm{pH}$. First of all, extract ligand substructure, then remove water and excess structure, finally, add hydrogens and fix sidechain amides. The protonated state of several important residues, such as GLU849, ASP810, ASP933, VAL851 and LYS802, were adjusted by using SYBYL6.9.1 (Tripos, St. Louis, MO, USA) in favor of forming reasonable hydrogen bond with the ligand. Molecular docking analysis was carried out by the SURFLEX-DOCK module of SYBYL 6.9.1 package to explore the binding model for the active site of PI3Ka with its ligand. All atoms located within the range of $5.0 \AA$ from any atom of the cofactor were selected into the active site, and the corresponding amino acid residue was, therefore, involved into the active site if only one of its atoms was selected. Other default parameters were adopted in the SURFLEX-DOCK calculations. All calculations were performed on a Silicon Graphics workstation. Lastly, docking results and the optimized molecular docking model with the receptor proteins was obtained $[3,7,9]$.

\section{Conclusions}

In summary, four series of 4-morpholino-7,8-dihydro-5H-thiopyrano[4,3- $d$ ]pyrimidine derivatives bearing phenylpyridine/phenylpyrimidine carboxamide scaffolds were designed, synthesized and evaluated for antitumor activity against three cancer cell lines and PI3K $\alpha$ kinase (only compound 12h) in vitro. The pharmacological results indicated that eleven of the compounds showed moderate cytotoxicity activity against the three cancer cell lines. In particular, the activity of the most promising compound 12h was equal to the positive control GDC-0941 against A549, with $n \mathrm{IC}_{50}$ value of $8.37 \pm 0.10$. Structure-activity relationships (SARs) indicated that the introduction of the phenylpyridine carboxamide scaffold was more favorable than the introduction of a phenylpyrimidine carboxamide scaffold for the activity. In general, the oxidation of a sulfur atom played no significant impact on the activity in the phenylpyridine carboxamide series, however, it could be appropriate to enhance the anti-tumor activity in the phenylpyrimidine carboxamide series. What's more, various types of substituents impacted differently on the activity of the four series of compounds. Furthermore, the position of substituents on aryl group played a slight role in the activity of the first two series of compounds. Further studies will be carried out in the near future.

Supplementary Materials: Supplementary materials are available online at http://www.mdpi.com/1420-3049/ 21/11/1447/s1.

Acknowledgments: We gratefully acknowledge the generous support provided by The National Natural Science Funds (No. 81460527 and No. 21662014), Science and Technology Project Founded by the Education Department of Jiangxi Province (No. GJJ150796), Top-notch talent project of Jiangxi Science \& Technology Normal University (2015QNBJRC001), Young Teachers Program of Universities in Shanghai (No. ZZyy15118).

Author Contributions: H. Liu, C. Sun, W. Wang and C. Wang synthesized all of novel compounds, P. Zheng run the bioassay evaluation and statistics analysis, W. Zhu started the project, designed the molecules and wrote the paper.

Conflicts of Interest: The authors declare no conflict of interest.

\section{References}

1. Janku, F.; Wheler, J.J.; Westin, S.N.; Moulder, S.L.; Naing, A.; Tsimberidou, A.M.; Fu, S.Q.; Falchook, G.S.; Hong, D.S.; Garrido-Laguna, I.; et al. PI3K/AKT/mTOR Inhibitors in Patients With Breast and Gynecologic Malignancies Harboring PIK3CA Mutations. J. Clin. Oncol. 2012, 30, 777-782. [CrossRef] [PubMed]

2. Yap, T.A.; Garrett, M.D.; Walton, M.I.; Raynaud, F.; de Bono, J.S.; Workman, P. Targeting the PI3K-AKT-mTOR pathway: Progress, pitfalls, and promises. Curr. Opin. Pharmacol. 2008, 8, 393-412. [CrossRef] [PubMed] 
3. Lei, F.; Sun, C.; Xu, S.; Wang, Q.; Ouyang, Y.; Chen, C.; Xia, H.; Wang, L.; Zheng, P.; Zhu, W. Design, synthesis, biological evaluation and docking studies of novel 2-substituted-4-morpholino-7,8dihydro-5H-thiopyrano[4,3-d]pyrimidine derivatives as dual PI3Ka/mTOR inhibitors. Eur. J. Med. Chem. 2016, 116, 27-35. [CrossRef] [PubMed]

4. Zhu, W.; Wang, W.; Xu, S.; Tang, Q.; Luo, R.; Wang, M.; Gong, P.; Zheng, P. Design, synthesis, and docking studies of phenylpicolinamide derivatives bearing $1 H$-pyrrolo[2,3- $b]$ pyridine moiety as c-Met inhibitors. Bioorg. Med. Chem. 2016, 24, 812-819. [CrossRef] [PubMed]

5. Zhu, W.; Wang, W.; Xu, S.; Wang, J.; Tang, Q.; Wu, C.; Zhao, Y.; Zheng, P. Synthesis, and docking studies of phenylpyrimidine-carboxamide derivatives bearing $1 H$-pyrrolo[2,3-b]pyridine moiety as c-Met inhibitors. Bioorg. Med. Chem. 2016, 24, 1749-1756. [CrossRef] [PubMed]

6. Zhu, W.; Sun, C.; Xu, S.; Wu, C.; Wu, J.; Xu, M.; Zhao, H.; Chen, L.; Zeng, W.; Zhen, P. Design, synthesis, anticanceer activity and docking studies of novel 4-morpholino-7,8-5H-thiopyrano[4,3-d]pyrimidine derivatives as mTOR inhibitors. Bioorg. Med. Chem. 2014, 22, 6746-6754. [CrossRef] [PubMed]

7. Sun, C.; Chen, C.; Xu, S.; Wang, J.; Zhu, Y.; Kong, D.; Tao, H.; Jin, M.; Zheng, P.; Zhu, W. Synthesis and anticancer activity of novel 4-morphlino-7,8-dihydro-5H-thiopyrano [4,3-d]pyrimidine derivatives bearing chromone moiety. Bioorg. Med. Chem. 2016, 24, 3862-3869. [CrossRef] [PubMed]

8. Sakamoto, T. Studies on pyrimidine derivatives. XVI. site selectivity in the homolytic substitution of simple pyrimidines. Chem. Pharm. Bull. 1980, 28, 571-577. [CrossRef]

9. Zhao, Y.; Zhang, X.; Chen, Y.; Lu, S.; Peng, Y.; Wang, X.; Guo, C.; Zhou, A.; Zhang, J.; Luo, Y.; et al. Crystal structures of PI3K $\alpha$ complexed with PI103 and its derivatives: New directions for inhibitors design. ACS Med. Chem. Lett. 2013, 5, 138-142. [CrossRef] [PubMed]

Sample Availability: Samples of the compounds $\mathbf{1 1 a}-\mathbf{1 1} \mathbf{j}, \mathbf{1 2 a}-\mathbf{1 2} \mathbf{j}, \mathbf{1 3 a}-\mathbf{1 3 g}$ and $\mathbf{1 4 a - 1 4 g}$ are available from the authors.

(C) 2016 by the authors; licensee MDPI, Basel, Switzerland. This article is an open access article distributed under the terms and conditions of the Creative Commons Attribution (CC-BY) license (http://creativecommons.org/licenses/by/4.0/). 